\title{
PENGARUH KEHILANGAN CAIRAN (DEHIDRASI) SAMPAI DENGAN 4\% TERHADAP KINERJA AN-AEROBIK
}

\author{
Y. Touvan Juni Samodra \\ Prodi Pendidikan Kepelatihan Olahraga, FKIP, UNTAN. \\ Email: tovan@fkip.untan.ac.id
}

\begin{abstract}
Abstrak
Penelitian ini dilatarbelakangi semakin banyaknya orang yang mengalami kelebihan berat badan. Orang akan berusaha untuk menurunkan berat badan secara instan. Kondisi ini berbahaya jika ditinjau dari tingkat dehidrasi jika terjadi kelebihan. Penelitian ini menggunakan prosedur pre test treatment dan post test. Sampel 25 mahasiswa kepelatihan olahraga semester 5 . Dehidrasi $4 \%$ dari $70 \%$ berat badan. Pengukuran dilakukan terhadap kemampuan anaerobik sebelum dan setelah dehidrasi $4 \%$. Treatment dehidrasi dengan menggunakan jas hujan. Data dianalis dengan menggunakan uji T. signigikansi analisis data menunjukkan $\mathrm{T}$ hitung 0.000 yang menunjukkan bahwa dehidrasi $4 \%$ dari $70 \%$ berat badan sangat mempengaruhi kinerja. implikasi dari penelitian ini adalah disarankan untuk tidak berlatih atau menurunkan berat badan sampai level $4 \%$ karena akan sangat menurunkan kinerja.yang kedua supaya asupan cairan selalu dijaga untuk mempertahankan hidrasi.
\end{abstract}

Kata kunci: dehidrasi, lari 400 meter.

\begin{abstract}
Background this research, many peoples were obesity. People tried to loss weight instantly. That is very danguares consider from hydrahtion level status. Research methods with pre-test and post-test experiments design. Sample consisted of 25 students of sports coaching education fifth semester. 4\% dehydration level was calculated based on $70 \%$ body weight. Procedures, weight measurements, 400 meters running test, 4\% dehydration calculation, and anaerobic test. Dehydration treatment $4 \%$ did by wearing a raincoat. $T$ he results of the calculation of the $T$ test significance of 0.000 showed differences in running achievement before and after dehydration. . The implication of the results study are for loss weight, it is very important to concern with hydration level so that performance achievement doesn't decrease, second need efforts to regulate fluid intake.
\end{abstract}

Keywords: dehydration, 400 running

PENDAHULUAN.

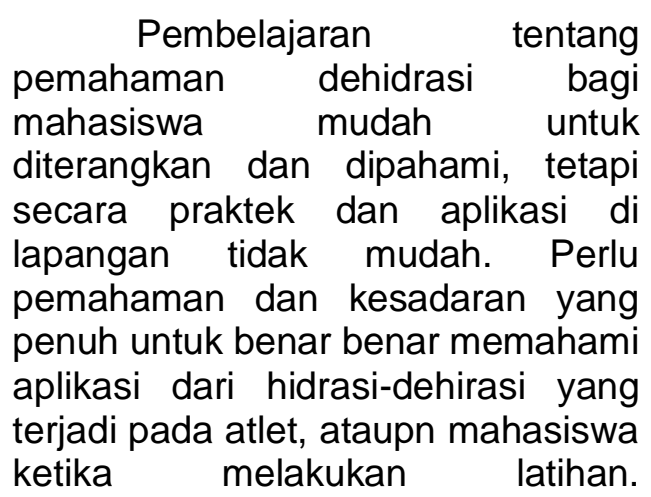

Keseimbangan cairan sangat penting. Jika berat badan seseorang $70 \mathrm{~kg}$ maka, 49-52,5kg adalah cairan. Berdasarkan kajian ini dapat disimpulkan bahwa air yang telah masuk ke dalam tubuh sangat berguna untuk proses mekanisme yang ada di dalam tubuh untuk mempertahankan regenerasi ataupun menjaga kestabilan. Keseimbangan air dalam tubuh diistilahkan dengan keseimbangan 
hidrasi, dalam hal ini ada proses dehidrasi (penurunan kadar air dalam tubuh) rehidrasi (pemulihan dari proses kehilangan cairan).

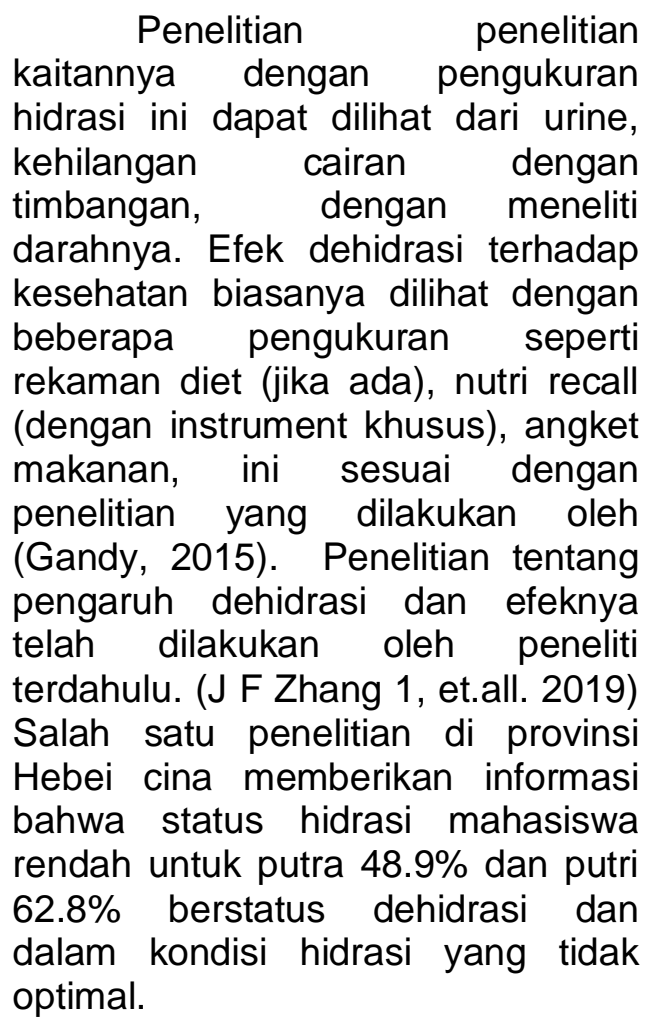

Peneltian yang dilakukan oleh (Sawka, Cheuvront, \& Kenefick, 2015) tentang efek kelebihan dan kekurangan air pada sistem butuh. Penelitian berikutnya menunjukkan bahwa emosi negatif, seperti marah, bingung, depresi tegang, rasa lelah meningkat ketika dehidrasi pada level di atas $1 \%$. Penelitian yang dilakukan (Perry, Rapinett, Glaser, \& Ghetti, 2015) pemberian asupan cairan memiliki efek yang positif terhadap kinerja otak, eksperimen dilakukan terhadap anak anak usia 9-12 tahun, dehidrasi sampai level $4 \%$ berakibat pada gangguan suasana hati, (Stevenson, Zabinsky, \& Hedrick, 2019) penelitian yang dilakukan terhadap pemain golf putri mengalami dehidrasi dan pemulihan, dalam kondisi dehidrasi prestasi mengalami penurunan tetapi tidak signifikan, kenyataan berikutnya setelah rehidrasi penampilan jauh meningkat. Berdasarkan penelitian ini terjadi penurunan konsentrasi; Penelitian yang dilakukan (Cvirn et al., 2019) probandus mengalami gangguan psikomotor dan kognisi (73 orang) dalam kondisi $33-35{ }^{\circ} \mathrm{C}$ :, (Pross, 2017) Hasil penelitian memberikan keseimpulan bahwa anak anak dan orang tua kognisi cenderung terganggu ketika mengalami dehidrasi (Hillyer, Menon, \& Singh, 2015) menyatakan $1 \%$ merupakan titik perbatasan ambang kognisi dan keteramilan gerak terganggu. Efek dari kehilangan cairan menimbulkan kerugian bagi yang mengalami dehidrasi. Pengukuran level dehidrasi (Belval et al., 2019) dapat dilakukan dengan membandingkan berat badan sebelum dan setelah olahraga serta catatan harian asupan cairan. Jika terjadi dehidrasi lebih besar dari 1.1\% maka akan terasa haus, warna urin lebih gelap. Penelitian (Magee, Gallagher, \& McCormack, 2017) penelitian menyebutkan $31.9 \%$ dari 430 setelah latihan terjadi kehilangan cairan $1.02 \%$ setelah latihan. Lebih lanjut Bukti menunjukkan bahwa pengetahuan tentang dehidrasi sangat rendah.

Berdasarkan penelitian terdahulu, maka kondisi kekurangan cairan hanya $1 \%$ pun sudah memiliki efek terhadap penurunan memori, semakin banyak kehilangan cairan akan memberikan efek yang semakin tidak baik. Data penelitian juga menunjukkan bahwa cukup 1$2 \%$ sudah menurunkan kinerja kognisi, motorik dan emosi. Hidrasi merupakan faktor yang penting bukan saja dalam bidang bagaimana mengoptimalkan kognisi, emosi , tetapi juga pada kinerja psikomotor. Status hidrasi perlu dipamahi oleh semua orang, bukan hanya olahragawan. 
Penelitian ini meneliti kehilangan cairan sampai dengan $4 \%$ dari $70 \%$ dari berat badan terhadap kinerja an aerobik. Penelitian ini bertujuan untuk mengetahui pengaruh dehidrasi terhadap kinerja. mengapa hal ini diteliti? Banyak orang yang ingin secara instan dan cepat melakukan penurunan berat badan. Ada dengan metode diet karbo ketat, sauna, lari menggunakan jaket mantel dan minum obat obatan pelangsing yang sifatnya deoritik. Informasi dari penelitian ini harapannya dapat menjadi rujukan untuk pelaksanaan diet penurunan berat badan yang aman.

\section{METODE}

Desain yang dipergunakan adalah eksperimen pre tes, treatment dan posttest. Penelitian dilaksanakan di Pontianak. Sampel penelitian 25 mahasiswa olahraga semester 5 .
Instrument pengambilan data

Beberapa peralatan yang dipergunakan dalam peneltian ini adalah timbangan berat badan, jas hujan, lintasan lari, stop watch. Data yang diperlukan adalah berat badan sebelum dehirasi, perhitungan dehirasi $4 \%$ dari $70 \%$ berat badan, kemampuan anaerob dengan lari 400 meter sebelum dan sesudah dehidrasi. Penelitian dilakukan dengan urutan, penimbangan, tes anaerob, perlakukan dehidrasi (dengan jas hujan), diakhiri dengan tes anaerob.

\section{Analisa data}

\begin{tabular}{lr}
\multicolumn{1}{c}{ Data } & dianalisis \\
membandingkan & perubahan \\
prestasi anaerob sebelum \\
dilakukan kehilangan cairan dan \\
setelah dehidrasi. Analisis dengan \\
menggunakan uji T.
\end{tabular}

HASIL

Deskripsi Hasil Penelitian

Tabel 1. Deskripsi hasil sebelum penelitian

\begin{tabular}{|c|c|c|c|}
\hline \multicolumn{4}{|c|}{ Statistics } \\
\hline & & sebelum & sesudah \\
\hline \multirow{2}{*}{$\mathrm{N}$} & Valid & 25 & 25 \\
\hline & Missing & 25 & 25 \\
\hline Mean & & 112.4800 & 146.3200 \\
\hline Median & & 105.0000 & 151.0000 \\
\hline Mode & & $82.00^{a}$ & $151.00^{a}$ \\
\hline
\end{tabular}

Data di atas memberikan pemahaman bahwa dehidrasi $4 \%$ sudah sangat cukup untuk menurunkan prestasi lari sampai $30 \%$.
Uji Prasaraf

\section{Normalitas}


Uji normalitas dengan Kolmogorov-smirnov, hipotesis null menyatakan populasi berdistribusi normal, jika statistik nilai sig. lebih besar dari a (0.05), data diasumsikan normal (Robert $\mathrm{H}$. Carver, p. 140. 2011). Hasil uji normalitas sebelum dehidrasi Sig. 0.077 dan setelah dehidrasi 0.068 .

Tabel 2. Hasil uji normalitas data

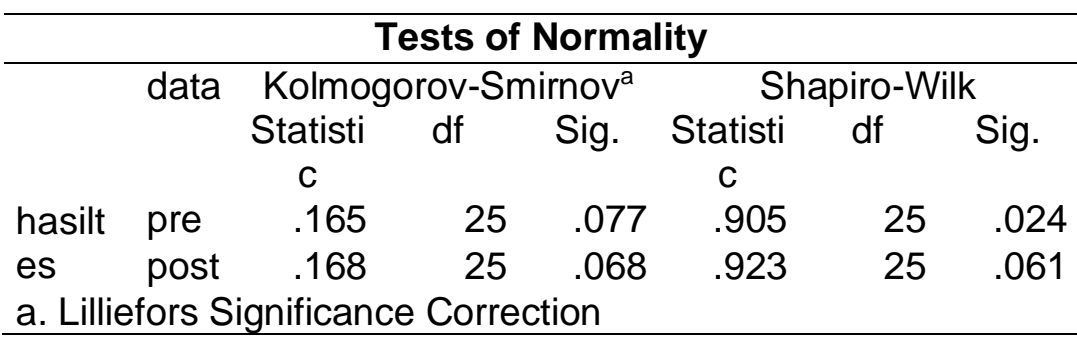

\section{Uji Homogenitas}

Tes homogenitas varian jika sig. lebih besar dari a (.05) maka hipotesis null diterima yang artinya varian homogen (Robert H. Carver, p. 156. 2011). Berdasarkan hasil tes homogenitas varian sig. 0.067> a 0.05 , maka dinyatakan homogen.

Tabel 3. Hasil uji homogenitas

\begin{tabular}{rrrrr}
\hline \multicolumn{5}{c}{ Test of Homogeneity of Variances } \\
\hline Levene Statistic & $\mathrm{df1}$ & $\mathrm{df2}$ & Sig. \\
5.178 & & 1 & 48 & .067 \\
\hline
\end{tabular}

3. Uji T

Berikut hasil perhitungan uji t.

Tabel 4. Hasil perhitungan uji $\mathrm{t}$

\begin{tabular}{|c|c|c|c|}
\hline \multicolumn{4}{|c|}{ Paired Samples Test } \\
\hline & & & $\begin{array}{c}\text { Pair } 1 \\
\text { sebelum - sesudah }\end{array}$ \\
\hline \multirow{5}{*}{$\begin{array}{l}\text { Paired } \\
\text { Differences }\end{array}$} & & -33.84000 \\
\hline & Std. Deviation & & 29.85895 \\
\hline & \multicolumn{2}{|l|}{ Std. Error Mean } & 5.97179 \\
\hline & \multirow{2}{*}{$\begin{array}{l}95 \% \text { Confidence } \\
\text { Interval of the } \\
\text { Difference }\end{array}$} & Lower & -46.16517 \\
\hline & & Upper & -21.51483 \\
\hline \multicolumn{3}{|c|}{ 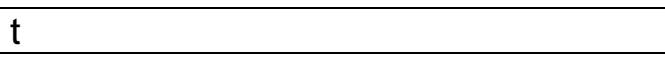 } & -5.667 \\
\hline \multicolumn{3}{|c|}{$\mathrm{df}$} & 24 \\
\hline \multicolumn{3}{|c|}{ Sig. (2-tailed) } & .000 \\
\hline
\end{tabular}

Uji $T$ hasil analisis data signigikansi hitung 0.000 , nilai tersebut lebih kecil dari 0.005 , sehingga dapat disimpulkan bahwa dehidrasi $4 \%$ berpengaruh terhadap prestasi an anerob.

\section{PEMBAHASAN}

Hasil penelitian memberikan gambaran bahwa dehidrasi level $4 \%$ dari $70 \%$ berat badan cukup untuk membuat penurunan prestasi sampai $30 \%$. Hal ini menjadi pertimbangan tersendiri bagi orang 
yang akan melakukan penurunan berat badan terlalu banyak dalam sekali waktu latihan. Terjadi lonjangan waktu yang sangat besar 33,84 detik. Argumentasi kedua, kinerja akan turun jika sampel mengalami dehidrasi sampai $4 \%$. Hasil penelitian lain memberikan penguatan bahwa dehidrasi memberikan dampak negatif terhadap kinerja, menurut (Cengiz, 2015) Dehidrasi menyebabkan penurunan pada power dan meningkatkan kelelahan serta berpengaruh terhadap kemampuan kardiovaskuler. Penelitian yang dilakukan oleh (Armstrong \& Johnson, 2018) memberikan data bahwa $71 \%$ orang usia $23-24$ tahun masih kurang dalam pemenuhan asupan cairan. Hal ini akan berakibat pada ganggunan metabolisme, transportasi di membransel, homoestatis sellluler, termogegulasi dan fungsi srikulasi. Penelitian (Barley, Chapman, Blazevich, \& Abbiss, 2018) orang coba (14 orang) dehidrasi sampai sampai $3,2 \%$ dan melakukan angkatan knee extensions at $85 \%$ dan dilaporkan persepsi kelelahan meningkat. Dehidrasi sampai 3.2\% berpengaruh terhadap strengthendurance dan meningkatkan persepsi kelalahan (Bardis et al., 2017). (Magee et al., 2017) menyatakan bahwa dehidrasi lebih dari $2 \%$ akan menurunkan daya tahan, beberapa penelitian lain menunjukkan pengaruh dehidrasi sebagai berikut, (Kraft et al., 2012) dehidrasi pada olahragawan sangat sering terjadi, batas ambang level yang mempengaruhi anaerobic adalah 3-4\%. Pada level dehidrasi sedang $3 \%$, kinerja akan terpengaruh dengan mimpertimbangkan intensitas dan recovery latihan, (Kraft et al., 2011) $3 \%$ sudah cukup untuk meningkatkan hematocrit. Bukti bukti penelitian memberikan gambaran bahwa penuruan berat badan harus dilakukan dengan aman. Angka terendah dalam penelitian ini dalah $2 \%$ dan angka tertinggi adalah 3,2\% sudah memberikan pengaruh yang tidak baik.

$\begin{array}{r}\text { Bagaimana } \\ \text { dehidrasi, }\end{array}$ (Maughan \&
status
Shirreffs, 2010b) $\begin{array}{r}\text { berpendapat, } \\ \text { diperlukan cara untuk menghitung }\end{array}$
level hidrasi, elektrolid dan subtansi
yang diperlukan selama dan setelah
latihan. Keseimbangan hidrasi
merupakan
menyeimbangkan jumlah air dalam
tubuh, dimana ada proses
kehilangan (dehidrasi) dan
pemenuhan/pemulihan (rehidrasi) agar fungsi tubuh tetap normal. penelitian dehidrasi (Bak, Tsiami, \& Greene, 2017) pengukuran hidrasi untuk orang tua , (Armstrong, 2005) beberapa metode cara mengukur hidrasi, (Armstrong, 2007); (Fortes et al., 2015) menyatakan bahwa darah dan urine belum tepat untuk menyatakan tingkat total jumlah cairan yang ada di dalam tubuh, (Hooper et al., 2016) urine dipergunakan untuk mengetes level hidrasi. Bagi pelaku penurunan berat badan, warna urine ini dapat menjadi indicator yang mudah untuk menilai level hidrasi. Jika urine sudah berwarna kuning pekat maka dipastikan level dehidrasi sudah parah, sehingga warna urine dijaga agar tetap bening, hal ini menandakan tubuh tidak sedang terjadi dehidrasi.

Sebagai bahan pertimbangan berkaitan dengan hasil penelitian dehirasi untuk kepentingan penurunan berat badan, menurut (Maughan \& Shirreffs, 2010b) sebelum latihan status hidrasi dapat dilihat dari warna urin. Cairan memiliki peran penting dalam berbagai proses fiologis tubuh. $70 \%$ dari berat badan manusia mengandung air. Kemampuan manusia bertahan hidup sangat 
tergantung dari cairan yang dimiliki. Oleh karena itu, terdapat berbagai mekanisme yang berfungsi untuk menyeimbangkan komposisi cairan dalam tubuh, seperti sistem kardiovaskuler, ginjal, paru, dan hati yang bekerja untuk menyeimbangkan komposisi cairan dalam tubuh. (Magee et al., 2017) Kenyataannya atlet yang mengawali latihan dengan minum mencapai hasil Lathan lebh baik. Menurut (S.S. et al., 2010) dalam pertandingan sepak bola dengan suhu 34-45 derajat Celsius rerata pemain bola kehilangan cairan 3.1 +/- 0.6 Liter. Kekurangan cairan atau dehidrasi dapat terlihat pada penurunan berat badan. (Maughan \& Shirreffs, 2010a) perubahan hidrasi saat latihan dapat diperkirakan dari perubahan jumlah keringat, dan jumlah urin yang keluar. Pendapat dari (Cengiz, 2015) pengaruh dehidrasi akan hilang setelah 12 jam istirahat.

Penelitian yang dilakukan (McDermott et al., 2015) membuktikan bahwa rehidrasi dengan asupan cairan memberikan efek positif terhadap kinerja kognisi pada anak dan orang dewasa. (McCartney, Desbrow, \& Irwin, 2017) Asupan cairan selama dehidrasi selama latihan dapat meningkatkan kinerja meskipun dalam konsidi lingkungan panas.

Penelitian (Harris et al., 2019) laki laki lebih cepat terjadi dehidrasi sampai 3\% dibandingkan dengan wanita. Berdasarkan percobaan ternyata air mineral laut sangat berpengaruh dalam pemulihan dehirasi. Dalam penetian ini dehirasi sampai $3 \%$ tidak mempengaruhi terhadap kekuatan. Pemulihan yang dilakukan dengan memberikan dua produk minuman dan air laut. Menurut (Holland, Skinner, Irwin, Leveritt, \& Goulet, 2017) bersepeda dengan intensitas moderat lebih dari 1 jam dan kurang dari 2 jam dianjurkan asupan cairan $0.15-0.20 \mathrm{~mL} / \mathrm{kg}$ body mass $/ \mathrm{min}$. Untuk bersepeda lebih dari 2 jam dengan intensitas moderat maka kebutuhan cairan antara 0.14$0.27 \mathrm{~mL} / \mathrm{kg}$ body mass $/ \mathrm{min}$. Menyatakan bahwa pengaturan asupan cairan menguntungkan bagi atlet dengan keuntungan pengaturan termoregulator (Barley et al., 2018). Penelitian lain memberikan petunjuk bahwa asupan cairan dengan kandungan alkaline dengan jumlah 2, 5 - 3 per 24 jam akan berpengaruh positif terhadap kinerja anaerobic (Maszczyk, 2018).

Berdasarkan pada kajian hidrasi dan penelitian tentang dehidrasi dapat disimpulkan bahwa, level hidrasi harus dipertahankan agar kinerja tubuh dapat terjadi dengan baik. Setiap level dehihidrasi akan memberikan efek yang berbeda, batas maksimal yang diperkenankan adalah $2 \%$ dan berkinerja pada durasi waktu kurang dari 90 menit. Level hidrasi turun maka akan memberikan pengaruh pada system sarat, dan metabolisme. Level dehidrasi ini dipengaruhi oleh suhu, intensitas kerja, dan durasi kerja. Cairan yang dimasukkan dapat berupa produk minuman khusus untuk olahraga yang mengandung mineral, salah satunya mengandung alkaline.

Penurunan berat badan dengan intensitas tinggi akan sangat menguras energy dan menguras cairan. Maka penelitian kaitan dengan kehilangan cairan terhadap kinerja sangat penting sebagai masukan secara praktis bagai pelaku olahraga ataupun orang awam agar lebih tajam dan teliti dalam melakukan latihan. Hal ini menunjukkan bahwa ada keterkaitan antara intensitas dengan level dehidrasi. dengan turunnya level 
hidrasi maka sudah dipastikan kinerja akan menurun.

Berdasarkan pada hasil
penelitian dan kajian relevan dapat
dipahami bahwa dehirasi akan
merugikan pelaku olahraga. Sehingga diperlukan cara agar level hidrasi terjaga sementara tujuan penurunan berat badan tetap tercapai. Review beberapa hasil penelitian menunjukkan bahwa pemenuhan hidrasi akan meningkatkan kemampuan anak dalam konsentrasi melihat, hal ini ditunjukkan oleh 5 penelitian (Edmonds et al., 2017) minum $25 \mathrm{ml}$ dapat meningkatkan kemampuan visual, dan minum $300 \mathrm{ml}$ dapat menurunkan rasa haus. Hasil penelitian (Campa et al., 2020) kondisi dehidrasi $2 \%$ terhadap atlet balap sepeda ternyata berpengaruh terhadap time trial dan menyebabkan aktiviasi otot menjadi lebih lemah. Penelitian oleh (Zhang, Du, Zhang, \& Ma, 2019) menunjukkan bahwa orang yang dehidrasi dengan prosedur tidak minum selama 36 jam tetapi diberi makan akan menurunkan memori jangka pendek, kecepaan membaca, semangat dan tingkat kelelahan yang lebih tinggi, dan sebaliknya ketika telah dilakukan rehidari terjadi pengingkatan yang signigikan terhadap variabel yang diteliti. Menurut (Patsalos \& Thoma, 2019) ternyata pemberian suplemen minuman $500 \mathrm{ml}$ setelah terjadi dehidrasi 12 jam sebelumnya dapat meningkatkan kinerja pengambilan keputusan. (Benton \& Young, 2015) hasil penelitian menyimpulkan bahwa dengan minum $300 \mathrm{ml}$ air dapat meningkatkan fungsi kognisi dengan percobaan memberikan 12 hal yang harus dihapalkan, (Pross, 2017) dehidrasi menyebabkan anak anak dan orang tua kognisi cenderung tergangggu ketika mengalami dehidrasi.
Penelitian penelitian di atas memberikan bukti bahwa status hidrasi yang baik akan memberikan efek yang baik terhadap kinerja. Pemberian cairan hanya $25 \mathrm{ml}$ sudah dapat sedikit membantu kemampuan visual, jika cairan yang ditambah semakin banyak yaitu 300 $\mathrm{ml}$ maka akan menjadikan efek lebih baik. Berbagai penelitian telah dilakukan, persentase terhadap kelihangan cairan. penelitian kaitan dengan kinerja dengan performe aktivitas olahraga masih sedikit tentang level dehidrasi di atas $2 \%$. Kajian olahraga dan aktivitas yang dilakukan sangat berdekatan erat dengan naik dan turunnya level cairan dalam tubuh. Kesalahan dan ketidakcermatan dalam menjaga hidrasi ini akan menentukan keberhasilan dalam latihan kajian literature, hasil penelitian dan pembahasan memberikan bukti bahwa aktivitas jasmani harus tetap menjaga status hidrasi. Khusus untuk orang latihan maka harus diperhatikan disarankan hanya sampai level $2 \%$ setiap kali latihan. Dehirasi level $2 \%$ ini berlaku juga untuk atlet dan orang awam.

\section{KESIMPULAN}

Penurunan berat sampai $4 \%$ dari $70 \%$ berat badan akan menurunkan kinerja an aerob sampai $30 \%$. Perlu dijaga level hidrasi pada kondisi aman, tidak sampai $2 \%$ untuk setiap kali latihan.

\section{Daftar Pustaka}

Armstrong, L. E. (2005). Hydration Assessment Techniques. Nutrition Reviews. https://doi.org/10.1111/j.17534887.2005.tb00153.x

Armstrong, L. E. (2007). Assessing Hydration Status: The Elusive Gold Standard. Journal of the American College of Nutrition, 26(5), 575S-584S. 
https://doi.org/10.1080/0731572 4.2007.10719661

Armstrong, L. E., \& Johnson, E. C. (2018). Water intake, water balance, and the elusive daily water requirement. Nutrients, 10(12), 1928.

https://doi.org/10.3390/nu10121 928

Bak, A., Tsiami, A., \& Greene, C. (2017). Methods of assessment of hydration status and their usefulness in detecting dehydration in the elderly. Current Research in Nutrition and Food Science. https://doi.org/10.12944/CRNF SJ.5.2.01

Bardis, C. N., Kavouras, S. A., Adams, J. D., Geladas, N. D., Panagiotakos, D. B., \&

Sidossis, L. S. (2017).

Prescribed drinking leads to better cycling performance than ad libitum drinking. Medicine and Science in Sports and Exercise, 49(6), 1244-1251. https://doi.org/10.1249/MSS.00 00000000001202

Barley, O. R., Chapman, D. W., Blazevich, A. J., \& Abbiss, C. R. (2018). Acute dehydration impairs endurance without modulating neuromuscular function. Frontiers in Physiology, 9, 1562. https://doi.org/10.3389/fphys.20 18.01562

Belval, L. N., Hosokawa, Y., Casa, D. J., Adams, W. M., Armstrong, L. E., Baker, L. B., ... Wingo, J. (2019). Practical hydration solutions for sports. Nutrients, 11(7), 1550. https://doi.org/10.3390/nu11071 550

Benton, D., \& Young, H. A. (2015). Do small differences in hydration status affect mood and mental performance? Nutrition Reviews. https://doi.org/10.1093/nutrit/nu v045

Campa, F., Piras, A., Raffi, M., Trofè, A., Perazzolo, M., Mascherini, G., \& Toselli, S. (2020). The effects of dehydration on metabolic and neuromuscular functionality during cycling. International Journal of Environmental Research and Public Health, 17(4), 1161.

https://doi.org/10.3390/ijerph17 041161

Cengiz, A. (2015). Effects of selfselected dehydration and meaningful rehydration on anaerobic power and heart rate recovery of elite wrestlers. Journal of Physical Therapy Science, 27(5)(Issue 5), 14411444.

https://doi.org/10.1589/jpts.27.1 441

Cvirn, M. A., Dorrian, J., Smith, B. P., Vincent, G. E., Jay, S. M., Roach, G. D., ... Ferguson, S. A. (2019). The effects of hydration on cognitive performance during a simulated wildfire suppression shift in temperate and hot conditions. Applied Ergonomics, 77, 9-15. https://doi.org/10.1016/j.apergo. 2018.12.018

Edmonds, C. J., Crosbie, L., Fatima, F., Hussain, M., Jacob, N., \& Gardner, M. (2017). Doseresponse effects of water supplementation on cognitive performance and mood in children and adults. Appetite, 108, 464-470.

https://doi.org/10.1016/j.appet.2 016.11.011

Fortes, M. B., Owen, J. A., 
Raymond-Barker, P., Bishop, C., Elghenzai, S., Oliver, S. J., \& Walsh, N. P. (2015). Is this elderly patient dehydrated? Diagnostic accuracy of hydration assessment using physical signs, Urine, and saliva markers. Journal of the American Medical Directors Association, 16(3), 221-228. https://doi.org/10.1016/j.jamda. 2014.09.012

Gandy, J. (2015). Water intake: validity of population assessment and recommendations. European Journal of Nutrition. https://doi.org/10.1007/s00394015-0944-8

Harris, P. R., Keen, D. A., Constantopoulos, E., Weninger, S. N., Hines, E., Koppinger, M. P., ... Konhilas, J. P. (2019). Fluid type influences acute hydration and muscle performance recovery in human subjects. Journal of the International Society of Sports Nutrition, 16, 15. https://doi.org/10.1186/s12970019-0282-y

Hillyer, M., Menon, K., \& Singh, R. (2015). Dehydration, SkillBased performance, Cognition, Motor-Skill performance; Dehydration, Skill-Based performance, Cognition, MotorSkill performance. International Journal of Sports Science, 99107. https://doi.org/10.5923/j.sports. 20150503.02

Holland, J. J., Skinner, T. L., Irwin, C. G., Leveritt, M. D., \& Goulet, E. D. B. (2017). The Influence of Drinking Fluid on Endurance Cycling Performance: A MetaAnalysis. Sports Medicine, 47, 2269-2284. https://doi.org/10.1007/s40279017-0739-6

Hooper, L., Bunn, D. K., Abdelhamid, A., Gillings, R., Jennings, A., Maas, K., ... Fairweather-Tait, S. J. (2016). Water-loss (intracellular) dehydration assessed using urinary tests: How well do they work? Diagnostic accuracy in older people. American Journal of Clinical Nutrition, 104(1), 121-31. https://doi.org/10.3945/ajcn.115 .119925

J F Zhang 1, N Zhang 1, H R He 1, H Cai 1, X H Guo 1, X Y Yan 1, Y B Li 1, M Zhang 1, G. S. M. 2. (2019). The Total Fluids Intake Among Young Adults From Hebei Province in Spring, 53(4), 345-349.

https://doi.org/10.3760/cma.j.iss n.0253-9624.2019.04.003.

Kraft, J. A., Green, J. M., Bishop, P. A., Richardson, M. T., Neggers, Y. H., \& Leeper, J. D. (2011). Effects of heat exposure and $3 \%$ dehydration achieved via hot water immersion on repeated cycle sprint performance. Journal of Strength and Conditioning Research, 25(3), 778-786. https://doi.org/10.1519/JSC.0b0 $13 \mathrm{e} 3181 \mathrm{c} 1 \mathrm{f} 79 \mathrm{~d}$

Kraft, J. A., Green, J. M., Bishop, P. A., Richardson, M. T., Neggers, Y. H., \& Leeper, J. D. (2012). The influence of hydration on anaerobic performance: A review. Research Quarterly for Exercise and Sport, 282-292. https://doi.org/10.1080/0270136 7.2012.10599859

Magee, P. J., Gallagher, A. M., \& McCormack, J. M. (2017). High prevalence of dehydration and inadequate nutritional 
knowledge among university and club level athletes.

International Journal of Sport

Nutrition and Exercise

Metabolism, 27(2), 158-168.

https://doi.org/10.1123/ijsnem.2 016-0053

Maszczyk, A. (2018). Anaerobic Performance and Acid-Base Balance in Basketball Players after the Consumption of Highly Alkaline Water. International Journal of Food and Nutritional Science.

https://doi.org/10.15436/23770619.18.1754

Maughan, R. J., \& Shirreffs, S. M. (2010a). Dehydration and rehydration in competative sport. Scandinavian Journal of Medicine and Science in Sports.

https://doi.org/10.1111/j.16000838.2010.01207.x

Maughan, R. J., \& Shirreffs, S. M. (2010b). Development of hydration strategies to optimize performance for athletes in high-intensity sports and in sports with repeated intense efforts. Scandinavian Journal of Medicine and Science in Sports.

https://doi.org/10.1111/j.16000838.2010.01191.x

McCartney, D., Desbrow, B., \& Irwin, C. (2017). The Effect of Fluid Intake Following Dehydration on Subsequent Athletic and Cognitive Performance: a Systematic Review and Metaanalysis. Sports Medicine Open. https://doi.org/10.1186/s40798017-0079-y

McDermott, B. P., Casa, D. J., Yeargin, S. W., Ganio, M. S., Lopez, R. M., Mooradian, E. a, ... Gait, H. (2015).
Deshidratacion $Y$

Sobrehidratacion Voluntarias.

Nutrition Reviews.

https://doi.org/10.1016/j.appet.2

012.10.016

Patsalos, O. C., \& Thoma, V. (2019). Water supplementation after dehydration improves judgment and decision-making performance. Psychological Research, 84, pages12231234. https://doi.org/10.1007/s00426018-1136-y

Perry, C. S., Rapinett, G., Glaser, N. S., \& Ghetti, S. (2015).

Hydration status moderates the effects of drinking water on children's cognitive performance. Appetite, 95, 520-527.

https://doi.org/10.1016/j.appet.2 015.08.006

Pross, N. (2017). Effects of Dehydration on Brain Functioning: A Life-Span Perspective. Annals of Nutrition and Metabolism, 70(1), 30-36. https://doi.org/10.1159/0004630 60

Robert H. Carver, J. G. N. (2011). Doing Data Analysis with SPSS $®$ Version 1. (Molly Taylor, Ed.). United States: Richard Stratton.

S.S., K., S.M., S., R.J., M., K.T., O., T., Z., S., K., ... J., D. (2010). Hydration and sweating responses to hot-weather football competition. Scandinavian Journal of Medicine and Science in Sports.

Sawka, M. N., Cheuvront, S. N., \& Kenefick, R. W. (2015). Hypohydration and Human Performance: Impact of Environment and Physiological 
Mechanisms. Sports Medicine. https://doi.org/10.1007/s40279015-0395-7

Stevenson, W., Zabinsky, J. S., \& Hedrick, V. E. (2019). Effects of Dehydration on Cognitive and Physical Performance in Female Golfers: A Randomized Crossover Pilot Study. Journal Multidicipline Scientific Science, 2, 496-507. https://doi.org/10.3390/j204003 2
Zhang, N., Du, S. M., Zhang, J. F., \& Ma, G. S. (2019). Effects of dehydration and rehydration on cognitive performance and mood among male college students in Cangzhou, China: A self-controlled trial. International Journal of Environmental Research and Public Health, 16(11), 1891. https://doi.org/10.3390/ijerph16 111891 